ORGANISATIONAL MATTERS

\title{
Improving safety on the front lines: the role of clinical microsystems
}

\author{
J J Mohr, P B Batalden
}

Qual Saf Health Care 2002;1 1:45-50

The clinical microsystem puts medical error and harm reduction into the broader context of safety and quality of care by providing a framework to assess and evaluate the structure, process, and outcomes of care. Eight characteristics of clinical microsystems emerged from a qualitative analysis of interviews with representatives from 43 microsystems across North America. These characteristics were used to develop a tool for assessing the function of microsystems. Further research is needed to assess microsystem performance, outcomes, and safety, and how to replicate "best practices" in other settings.

See end of article for authors' affiliations

Correspondence to DrJ J Mohr, Schools of Public Health and

Pharmacy, The University of North Carolina at Chapel Hill, CB\#7360 Beard Hall, Chapel Hill, NC 27599-7360, USA; Julie_mohr@unc.edu

Accepted for publication 7 January 2002
$\mathrm{H}$ ealth care is provided to patients by caregivers who work in complex organisational arrangements, but the overwhelming amount of their own daily work is as part of "clinical microsystems". The basic concept of clinical microsystems-small organised groups of providers and staff caring for a defined population of patients-is not new. One can envisage microsystems existing in every healthcare setting-primary care clinics, neonatal intensive care units, renal dialysis units, diabetes care clinics, etc. However, often people lack awareness of the elements and the dynamics of the small systems in which they work. Microsystems are often not recognised as a functioning unit by the larger organisations that provide the organisational context for their work. Research has been important in identifying the extent and general causal pathways of errors in health care. Additional research is needed to develop and test better ways to prevent errors and improve patient safety at the microsystem of healthcare deliverywhere patients and providers meet at the front lines of patient care.

The IOM report "To err is human: building a safer health system" estimated that 44000-98000 people die each year die from medical errors. ${ }^{1}$ Even the lower estimate is higher than the annual mortality from motor vehicle accidents (43 458), breast cancer (42 297), or AIDS (16 516), thus making medical errors the eighth leading cause of death in the United States.

Although errors in medication, ${ }^{2}$ surgery, ${ }^{3}$ and diagnosis are the easiest to detect, medical errors may result more frequently from the organisation of healthcare delivery. For example, Leape and colleagues ${ }^{4}$ discovered that failures at the system level were the real culprits in over $75 \%$ of adverse drug events. Reason et al suggested that some systems are more vulnerable and therefore more likely to experience adverse events. Certain organisational pathologies contribute to what Reason refers to as "vulnerable system syndrome" - blaming front line individuals, denying the existence of systemic error provoking weaknesses, and the blind pursuit of the wrong type of performance measures (for example, financial and production indicators).

The recommendations contained in the IOM report ${ }^{1}$ emerged from a four-tiered strategy (box $1)$, the fourth of which is the ultimate target of all the recommendations and the objective of this paper, which is to give an overview of the concept of clinical microsystems and to offer an assessment tool for those wishing to initiate improvements in the safety of care for patients and populations in microsystems. This tool, which was developed from the results of a cross-case analysis of 43 microsystems, can be used to help form an "awareness" of the microsystem and its functioning. The clinical examples provided throughout the paper are based on our experience in the United States. ${ }^{6}$ Working at the level of the microsystem, it is possible to develop generalisable methods for application across macroorganisation settings for error reduction.

\section{INTRODUCTION TO CLINICAL MICROSYSTEMS}

The "organisation" has been the conventional level of analysis for management of diverse types of healthcare personnel. Some attention has focused on the design of work units within the organisation, such as medical staff, ${ }^{7}$ surgical staff, ${ }^{8}$ nursing staff, support groups, interdisciplinary teams, ${ }^{9}$ and the applicability of these work units to specific areas of care such as aging, long term care, renal therapy, and oncology. In general, however, research at the level of the microsystem

\section{Box 1 IOM recommendations}

- Establish a national focus on patient safety by creating a centre for patient safety within the Agency for Healthcare Research and Quality.

- Identify and learn from errors by establishing nationwide mandatory and voluntary reporting systems.

- Raise standards and expectations for improvement in safety through the actions of oversight organisations, group purchasers, and professional groups.

- Create safety systems inside healthcare organisations through the implementation of safe practices at the delivery level. 
within the organisation has received limited attention. Social policy has also focused at the organisational level and individual provider level, thus missing the potential contribution of how the structures and strategies of the microsystem affect patient outcomes as well as affect the performance of the microsystem.

Research in managing safety has focused on the culture and structure of the organisation. ${ }^{10}{ }^{11}$ Perrow $^{10}$ advanced the theory that accidents are inevitable in complex, tightly coupled systems such as chemical plants and nuclear power plants. These accidents occur irrespective of the skill of the designers and operators, hence they are "normal" and are difficult to prevent. He further argues that, as systems get more complex, the system becomes opaque to its users and therefore people forget to be afraid of potential adverse occurrences. Organisational models view human error more as a consequence than a cause, and stress the need for proactive measures of "safety and health" with constant reform of the systems processes. Both Perrow and Vaughn emphasise the structural and organisational dimensions or organisational processes, making the case for assessing the operations of an organisation which we extrapolate to the microsystem. Finally, organisational flexibility means possessing a culture capable of adapting to changing demands. High reliability organisations $\left(\right.$ HROs) ${ }^{12}$ are an example of highly complex technology sensitive organisations that must operate to a failure free standard. Examples include naval aircraft carriers and air traffic control. These organisations carry out demanding activities with a very low error rate and an almost complete absence of catastrophic failure over many years.

The microsystem concept is based on an understanding of systems theory ${ }^{13-15}$ coupled with James Brian Quinn's theory of a smallest replicable unit. ${ }^{16}{ }^{17}$ Nelson and colleagues ${ }^{18}$ have described the essential elements of a microsystem as (a) a core team of healthcare professionals; (b) the defined population they care for; (c) an information environment to support the work of caregivers and patients; and (d) support staff, equipment, and a work environment. A focus on microsystems is a way to provide (1) greater standardisation of common activities and customisation of care to individual patients, (2) greater use and analysis of information to support daily work, (3) consistent measured improvement in performance, (4) extensive cooperation and teamwork across disciplines and specialties within the microsystem, and (5) an opportunity for spread of best practices across microsystems within their larger organisations. ${ }^{18}$

\section{MAKING THE LINK BETWEEN SAFETY AND THE MICROSYSTEM}

Initiating the improvement of the safety of care for patients and populations in clinical microsystems involves increasing the work unit's "awareness" of its functioning as a microsystem and a "mindfulness" of its reliability. We usually think of awareness and mindfulness as things to which individuals aspire. These reflective states are an invitation to consider the clinical microsystem to be composed of individuals who function together as systems, capable of reflecting on their work. Awareness of one's own work unit as a system is a matter of identity and is connected to purpose. Learning to increase the safety and reliability of organisations can be addressed in many ways. ${ }^{19-22}$ Weick and Sutcliffe offer the idea that HROs have become so by their "mindfulness." ${ }^{23}$ By mindfulness they mean that these organisations are:

- Preoccupied with failure: they "treat any lapse as a symptom that something is wrong with the system, something that could have severe consequences if separate small errors happen to coincide at one awful moment."

- Reluctant to simplify interpretations: they "take deliberate steps to create more complete and nuanced pictures. They simplify less and see more. Knowing that the world they face is complex, unstable, unknowable, and unpredictable, they position themselves to see as much as possible."

- Sensitive to operations: they recognise that "unexpected events usually originate in what James Reason called "latent failures". These "loopholes in the system's defences, barriers and safeguards ... consist of imperfections in ... supervision, reporting of defects, engineered safety procedures, safety training, briefings, certification, and hazard identification. Normal operations may reveal these lessons, but [they] are visible only if they are attentive to the front line, where the real work gets done."

- Committed to resilience: they "develop capabilities to detect, contain, and bounce back from those inevitable errors that are part of an indeterminate world .... [they are not errorfree, but errors don't disable them] ... it is a combination of keeping errors small and of improvising workarounds that keep the system functioning."

- Deferent to expertise: they encourage decisions to be made at the front line and migrate authority to the people with the most expertise, regardless of rank.

According to Weick and Sutcliffe, becoming more mindful means practising more of these behaviours. Mindfulness implies "a radical presentness" and a connection to the actual requirements of the current situation along with a chronic sense of unease that something catastrophic might occur at any moment. This sense is inculcated to all members of the unit, from the leaders to the most junior people on the team.

The relationship between mindfulness and the microsystem requires further clarification. The focus on microsystems invokes consideration of team performance and the relationship of individuals within teams. The idea of high reliability organisations suggests that team and individual performance depends on the development of certain organisational norms. Such cultural attributes are commonly seen as properties of larger systems than teams. Is it possible for mindful microsystems to exist in dysfunctional organisations? In considering this possible relationship between a "mindful" microsystem and a dysfunctional organisation, it is important to recognise the importance of the larger system to the success or failure of the microsystem, as reported by an interviewee at a geriatric unit when asked about how the larger system has supported the efforts of the microsystem:

"The administration has continued to support the geriatric unit by providing both staffing and general resources. Getting a 'yes' for a request from the administration depends on how they feel about you and your department. On the converse, rarely do units exist in a vacuum. So, where there is a larger structure, there are always potential negatives."

Furthermore, a focus at the microsystem level changes the role of senior leadership_-indeed, this is not a minor detail. The Health Care Advisory Board reported that a common ingredient in successful organisations is a "tight, loose, tight" deployment strategy. ${ }^{24}{ }^{25}$ What might this mean for creating a microsystem striving to provide safer care? It would mean that senior leaders would mandate that each microsystem should have a "tight" alignment of its mission, vision, and strategies with the organisation's mission, vision, and strategies. But it would also mean that senior leadership gives each microsystem the flexibility needed to achieve its mission. Finally, it would mean that senior leaders hold the microsystems accountable to achieve its strategic mission to provide safer care.

\section{LEARNING FROM CLINICAL MICROSYSTEMS}

We have worked with several microsystems seeking to improve their care for patients. Some of them seemed to have a clear sense of their identity as a system and, when they 
Box 2 Characteristics of effective microsystems

- Integration of information

- Measurement

- Interdependence of the care team

- Supportiveness of the larger system

- Constancy of purpose

- Connection to the community

- Investment in improvement

- Alignment of role and training

Table 1 Summary of microsystem characteristics

\begin{tabular}{|c|c|}
\hline Characteristic & Operational definition \\
\hline & $\begin{array}{l}\text { ion is key, technology may be } \\
\text { pful }\end{array}$ \\
\hline & $\begin{array}{l}\text { stem routinely measures processes } \\
\text { comes feeds data back to } \\
\text { rs, makes changes based on data }\end{array}$ \\
\hline $\begin{array}{l}\text { Interdependence of } \\
\text { care team }\end{array}$ & $\begin{array}{l}\text { by a multidisciplinary } \\
\text { tion is key to the relationship }\end{array}$ \\
\hline eness of the & $\begin{array}{l}\text { - Microsystem views larger organisation as } \\
\text { helpful }\end{array}$ \\
\hline Constancy of purpose & $\begin{array}{l}\text { - Integration of the aim throughout the } \\
\text { microsystem }\end{array}$ \\
\hline $\begin{array}{l}\text { Connection to } \\
\text { community }\end{array}$ & $\begin{array}{l}\text { - Microsystem is a resource to the } \\
\text { community, community is a resource to the } \\
\text { microsystem }\end{array}$ \\
\hline $\begin{array}{l}\text { Investment in } \\
\text { improvement }\end{array}$ & $\begin{array}{l}\text { - Resources made available for } \\
\text { improvement (training, money, time) }\end{array}$ \\
\hline $\begin{array}{l}\text { Alignment of role and } \\
\text { training }\end{array}$ & $\begin{array}{l}\text { - Health professionals expected to work at } \\
\text { the upper limits of education, training }\end{array}$ \\
\hline
\end{tabular}

explored change for the improvement of their functioning, they were able to incorporate the change and make it a regular part of their identity as a system. Others-lacking a similar sense-pursued change just as diligently, but seemed to have difficulty incorporating that change into their "system". As we have begun to tease out the characteristics of the apparently better functioning small systems, certain elements or characteristics have emerged.

As part of a study funded by the Robert Wood Johnson Foundation, ${ }^{6}$ interviews were conducted with representatives from 43 microsystems and eight characteristics present across multiple microsystems were identified (box 2). The methods used for this study are discussed in detail elsewhere. ${ }^{626}$

Each of the dimensions can be thought of on a continuum that represents the presence of the characteristic in the microsystem. Table 1 summarises the characteristics and provides an operational definition for each of them. Increased awareness of the small front line work unit as a microsystem means recognising the characteristics that contribute to their identity (the elements described in table 1) and being mindful of the reliability of these characteristics. A more detailed description of each of the characteristics is given below with verbatim comments from the interviews.

\section{Integration of information}

Universal among high performing microsystems is integration of information. Microsystems vary on how well information is integrated into its daily work and the role that technology plays in facilitating the integration. An illustrative comment from a microsystem operating in an "information free environment" follows:

"If you aren't going to have the same nurse working with the patient then you have to have better communication. Patients get the best care when you have health care workers who communicate very well and collaborate very well. One of the biggest problems I see is physicians not talking to each other. Also, so many nurses work part-time, varying shifts. We struggle with getting them to communicate. It's hard to get them to put equal emphasis on communicating, documenting, teaching and the physical tasks that need to be done before the end of the shift. You don't get the same negative feedback from your coworkers if you aren't teaching the patient as you do if you leave some of the physical tasks undone at the end of the shift. A nurse will prioritize and get every thing done before the end of the shift, but they don't look at the patient's care plan and do the teaching that needs to be done before discharge."

Deming taught that knowledge is built on theory, not information. ${ }^{27}$ According to Deming, information is static whereas knowledge has a temporal spread. Put simply, with knowledge a theory can be developed that explains what happened in the past and predicts what will happen in the future. It is the integration of the information that allows us to create knowledge. Technology can be instrumental in facilitating the integration of information within the microsystem.

"Sharing information with patients is the biggest safeguard against medical error. The electronic medical record (EMR) does drug-drug interaction alerts. When the patient leaves the office, he/she gets a printout of their medication list. Once in a while a patient will call later and say, 'I was looking over the list, and I am not taking $x$ anymore, but Dr So and So has put me on y.' It takes all of us. Another safeguard is that the system we use forces me to consider all the possibilities. For example, if a patient comes in with headaches and vomiting, it has a structured sequence that makes you consider the causes, including cerebral hemorrhage."

\section{Measurement}

Effective microsystems measure what they do and recognise that the measures at the macrosystem level are not always helpful at the microsystem level. Part of the work of the microsystem becomes the development of a set of measures that are appropriate for the goals of the microsystem. As one interviewee concluded:

"At the local level I don't get the measures that I need and the measures at the regional level aren't at the level I need."

It may be that this recognition is important in developing a microsystem that routinely measures processes and outcomes, feeds data back to providers, and makes changes based on data.

"We can track process length through our real time 'flight simulator' system. By touching the screen, we instantly know such things as arrival to bed, bed to nurse, arrival to doctor aggregated cycle times."

\section{Interdependence of care team}

Key players - the providers and staff who work together on a daily basis - are a fundamental element of the microsystem. However, the interdependence of these key players tends to vary across microsystems. Microsystems with a high degree of interdependence are mindful of the importance of the multidisciplinary team approach to care, whereas those with a lower degree of interdependence are characterised by providers and staff working as individuals with no clear way of sharing information or communicating.

"We developed multidisciplinary rounds—everyone involved in caring for the patient. The major value is having everyone communicate directly with one another. Each person knows they may be asked about the patients and has to be prepared."

"Often physicians have difficulty working with non-physician providers, giving them the control. Some physicians don't do well sharing responsibility for patient care like this."

\section{Supportiveness of the larger system}

The larger organisation may be either helpful or "toxic" to the efforts of the microsystem.

"The hospital system has shown great effort in helping us out with patient restraint protocols. Restraint management has been an area where they have excelled and this has made the ER a safe place to work. They are also helping us out in quality end-of-life issues and how cultural differences of people necessitate individualized care." 
"It is a mixed message. The organisation talks about team care but then subverts their vision - they put in a centralized phone system with a nurse in charge of scheduling appointments. Well, she has no way of knowing whether Drs $X$ and $Y$ are on the same team. If a patient of Dr $X$ cannot go to Dr $X$ because he is on vacation, the nurse may send the patient to Dr Z though Dr Y is on Dr X's team. So instead of the patient going to $\operatorname{Dr} Y$, they go to Dr Z."

\section{Constancy of purpose}

An important characteristic of a microsystem is that the aim, or what Deming would refer to as "the constancy of purpose ${ }^{\prime \prime},{ }^{27}$ is consistent with the aim of the larger system and guides the work of the microsystem. Where constancy of purpose is high, the aim is apparent to the microsystem, and it is also communicated across the boundaries of the microsystem.

"The thing that distinguished those places that are achieving excellence is the organizational culture. Our culture was 'of course babies [in the NICU] get infections, they are not well to begin with'. But those other sites saw an infection as a failure, not entitlement. All the way to the bedside the unit knew that infection was a failure. The philosophy has to permeate the organization."

In contrast, lack of a clear consistent aim may be destructive to the microsystem and, ultimately, to patient care.

"There are various ways that health care workers let patients know that we are busy-don't tell us that you are having a problem because we don't have time to deal with that. For a lot of nurses the reason for being a nurse was to relieve pain and suffering. But then we send the message that we don't have time to help you."

\section{Connection to community}

Connection to community represents a symbiotic relationship between the microsystem and the community that extends well beyond the clinical care of a defined set of patients.

"The neonatology group has a commitment of being a resource to the region. We have a commitment to the health of a population. This is crucial to our success. As a resource, we provide education and review the quality of care for the whole region."

\section{Investment in improvement}

An investment in improvement comes in the form of resources such as time, money, and training, but above all it involves creating a philosophy of improvement within the microsystem. This characteristic overlaps with "supportiveness of the larger organisation" and suggests an obvious way in which the larger organisation can support the work of the microsystem.

"In a given week we are spending about 100 person-hours on teams. People are being paid to spend their time doing this, not just during their lunch hour. Someone said, 'You have to assume you'll be around here 5 years from now. Do you want to be doing things the same way?' Most of us don't. This requires a new attitude that results in understanding that industries must invest in change in these microsystems. You have to tolerate pulling people off-line to work. This is a radically new way of thinking in medicine, which traditionally views any sort of meeting as a waste of time. Traditionally, the view is that the only useful time is spent seeing patients. I think that unless you spend time considering how to deliver care better, much of that time seeing patients is wasted."

\section{Alignment of role and training}

Alignment of role and training suggests that there is a deliberate effort within the multidisciplinary team to match the team member's education, training, and licensure with their role. While several interviewees indicated that this leads to increased staff satisfaction and lower turnover, some are uncomfortable working in what they consider to be an "expanded" role. As one interviewee said: "casualties move on to other parts of the hospital".

"The system can be an advocate. It can be a reminder that a mammogram needs to be done, that there is a system in place to make sure it happens, that things go well. A system can empower the medical assistant to insist that a patient be seen, even if it means clashing with a provider."
Key messages

- A clinical microsystem is a small organised group of clinicians and staff working together with a shared clinical purpose to provide care for a defined set of patients.

- The clinical purpose defines the essential parts of the microsystem. Use of information is key to its ability to function; information technology facilitates collecting, assessing, and sharing of information.

- Microsystems are usually part of a larger organisation and are embedded in a legal, financial, social, and regulatory environment.

- Answers to the following questions are needed to define the microsystem:

- what is the aim or purpose?

- who is the small population of people who benefit from this aim?

- who do you work with daily ladministratively, technically, and/or professionally)?

- what information and information technology is part of the daily work?

- Senior leaders of the microsystem should:

- look for ways in which the macro-organisation connects to and facilitates the work of the microsystem;

- support the needs of the microsystem;

- facilitate the coordination among microsystems.

\section{IMPROVING THE QUALITY AND SAFETY OF CARE IN THE MICROSYSTEM}

The eight characteristics discussed above were used to create a self-assessment tool (shown in Appendix on page 50) for individuals to assess the functioning of their microsystem and to identify potential areas to focus improvements. We have observed that use of the tool is successful in facilitating discussions around ideas for individual microsystems trying to foster further development of their system and/or a given characteristic.

Several limitations apply to the use of this assessment tool in its present form. Each represents an opportunity for further empirical testing and research. Firstly, we recognise that increasing the strength of an attribute or characteristic does not necessarily increase the overall functioning of the unit as a system. We make the assumption that, as efforts are made to increase the expression of a characteristic in a microsystem, efforts are concurrently being undertaken to integrate the newly expressed element into the functioning of the enhanced unit as a better functioning system. Secondly, we recognise the need for further testing, development, and validation of the assessment tool. However, we caution people about waiting for the "perfect" method or tool if there are tools available that are useful as you try to improve awareness of the functioning of your microsystem. Finally, we make the assumption that a better functioning microsystem provides safer care and achieves better outcomes for its patients.

\section{CONCLUSIONS}

The concept of microsystems and the assessment tools to assess and evaluate characteristics of a microsystem can make a great contribution to the future study and management of patient safety. We believe that most health care today is sought, created, delivered, and purchased at the level of the clinical microsystem. It is there that real gains in the quality, value, and safety of care can occur. Furthermore, we believe that efforts to increase awareness and mindfulness at the level of the clinical microsystem can contribute to the safety of patient care. Combining organisational characteristics with an analysis of the characteristics of an individual microsystem 
offers a powerful way to visualise the link between structure, process, and outcomes and to make practical what is theoretically attractive. ${ }^{28}$

The implications of the microsystem framework for the delivery of care are much broader than just for a given microsystem and the people working within it. There is a need for ongoing research into microsystems, how to assess their functioning, performance, outcomes, and safety, and how to replicate "best practices" in other settings. Clinical leaders can find new energies for common efforts to study and improve their work for patients as they gather around the focus of the actual unit of daily practice-crossing disciplinary and specialty boundaries-using the language of processes and systems, rather than the more conventional role or disciplinebound conversations that often seem to limit change and improvement. If the microsystem is a new frontier in organisational and health services management research, further research is needed to understand the contributions of practice based research in improving the delivery of safer care.

\section{Authors' affiliations}

J J Mohr, Schools of Public Health and Pharmacy, The University of North Carolina at Chapel Hill, NC 27599-7360, USA

P B Batalden, Center for the Evaluative Clinical Sciences, Dartmouth Medical School, Hanover, New Hampshire, USA

\section{REFERENCES}

1 Institute of Medicine. To err is human: building a safer health system. Washington, DC: National Academy Press, 1999

2 Leape LL, Brennan TA, Laird N, et al. The nature of adverse events in hospitalized patients. Results of the Harvard Medical Practice Study-ll. N Engl J Med 1991;324:377-84.

3 Gawande AA, Thomas EJ, Zinner M, et al. The incidence and nature of surgical adverse events in Colorado and Utah in 1992. Surgery 1999; 126:66-75.

4 Leape LL, Bates DW, Cullen DJ, et al. Systems analysis of adverse drug events. JAMA 1995;274:35-43.

5 Reason JT, Carthey J, de Leval MR. Diagnosing "vulnerable system syndrome": an essential prerequisite to effective risk management. Qual Health Care 2001;10(suppl II):ii2 1-5.

6 Donaldson MS, Mohr JJ. Improvement and innovation in health care micro-systems. A Technical Report for the Institute of Medicine Committee on the Quality of Health Care in America. Princeton: Robert Wood Johnson Foundation, 2000 (available on the National Academy of Sciences website: http://books.nap.edu/catalog/10096.html).

7 Shortell S. The medical staff of the future: replanting the garden. Frontiers Health Serv Manage 1985;1:3-48.

8 Flood A. Effectiveness in professional organizations: the impact of surgeons and surgical staff organizations on the quality of care in hospitals. Health Serv Res 1982;17:341-66.

9 Kaluzny AD. Design and management of disciplinary and interdisciplinary groups in health services: review and critique. Med Care Rev 1985;42:77-1 12 .

10 Perrow C. Normal accidents: living with high-risk technologies. New York, Basic Books, 1984.

11 Vaughn D. The Challenger launch decision, Chicago: Chicago University Press, 1996.

12 LaPorte TR, Consolini PM. Working in practice but not in theory: theoretical challenges of "high-reliability organizations". J Public Admin Res Theory 1991;1:21.

13 von Bertalanffy L. General system theory. In: Rapoport A, ed. General systems. Yearbook of the Society for the Advancement of General Systems Theory, 1956.

14 Scott RW. Organizations: rational, natural, and open systems. Englewood Cliffs, NJ: Prentice Hall, 1981.

15 Boulding K. General systems theory: the skeleton of science. Management Sci 1956;2:197-208.

16 Quinn JB. The intelligent enterprise. New York: Free Press, 1992.

17 Quinn JB, Baruch JJ, Zien KA. Innovation explosion: using intellect and software to revolutionize growth strategies. New York: Free Press, 1997.

18 Nelson EC, Batalden PB, Mohr JJ, et al. Building a quality future. Frontiers Health Serv Manage 1998;15:3-32.

19 Reason JT. Human error. New York: Cambridge University Press, 1990

20 Reason JT. Managing the risks of organizational accidents. Aldershot: Ashgate, 1997.

21 Bogner MS, ed. Human error in medicine. Hillsdale, NJ: L Erlbaum Associates, 1994.

22 Weiner E, Kanki B, Helmreich R. Cockpit resource management. 1993.

23 Weick K, Sutcliffe K. Managing the unexpected: assuring high performance in an age of complexity. San Francisco: Jossey-Bass, 2001 24 Health Care Advisory Board. Run to rigor. Washington, DC: Health Care Advisory Board, 1997.

25 Caldwell $C$. The role of senior leaders in driving rapid change. Frontiers Health Serv Manage 1998;15:35-9.

26 Mohr JJ. Forming, operating, and improving micro-systems of health care. Dartmouth College, 2000.

27 Deming WE. The new economics for industry, government, education Cambridge, Mass: Massachusetts Institute of Technology Center for Advanced Engineering Study, 1993.

28 Goldberg HI. Building healthcare quality: if the future were easy, it would be here by now. Frontiers Health Serv Manage 1998;15:40-2. 
Instructions: Each of the following themes (e.g. integration of information) is followed by a series of descriptions. For each theme, please check the description that best describes your current microsystem and delivery of care.

\begin{tabular}{|c|c|c|c|c|}
\hline Theme & Descriptions & & & \\
\hline $\begin{array}{l}\text { Integration of information } \\
\text { with providers and staff }\end{array}$ & $\begin{array}{l}\square \text { We are always tracking down the } \\
\text { information we need to do our work }\end{array}$ & $\begin{array}{l}\square \text { Most times we have the information we need, } \\
\text { but other times essential information is missing } \\
\text { and we have to track it down }\end{array}$ & $\begin{array}{l}\square \text { We get the right information at the right } \\
\text { time to perform our work }\end{array}$ & $\begin{array}{l}\square \text { Can't }^{\prime} \\
\text { rate }\end{array}$ \\
\hline $\begin{array}{l}\text { Integration of information } \\
\text { with patients }\end{array}$ & $\begin{array}{l}\square \text { Generic reading materials are available } \\
\text { in patient areas }\end{array}$ & $\begin{array}{l}\square \text { Standardised information is offered } \\
\text { to all patients based on the diagnosis }\end{array}$ & $\begin{array}{l}\square \text { We offer comprehensive information to address } \\
\text { patients' different learning styles. The information } \\
\text { is customised to meet the patient's needs }\end{array}$ & $\begin{array}{l}\square \text { Can't }^{\prime} \\
\text { rate }\end{array}$ \\
\hline $\begin{array}{l}\text { Integration of information } \\
\text { with technology }\end{array}$ & $\begin{array}{l}\square \text { Patient records are paper based in our } \\
\text { microsystem }\end{array}$ & $\begin{array}{l}\square \text { Our patient records and financial systems are } \\
\text { computer based, but separate }\end{array}$ & $\begin{array}{l}\square \text { Our patient records and financial systems } \\
\text { are to some extent or entirely integrated }\end{array}$ & $\begin{array}{l}\square \text { Can't }^{\prime} \\
\text { rate }\end{array}$ \\
\hline Measurement & $\begin{array}{l}\square \text { We don't track results of the care we } \\
\text { provide on a regular basis }\end{array}$ & $\begin{array}{l}\square \text { We systematically collect data on } \\
\text { the results of the care we provide }\end{array}$ & $\begin{array}{l}\square \text { We routinely collect data on the results of the care } \\
\text { we provide, feed data back to providers, and make } \\
\text { changes based on data }\end{array}$ & $\begin{array}{l}\square \text { Can't }^{\prime} \\
\text { rate }\end{array}$ \\
\hline $\begin{array}{l}\text { Interdependence of } \\
\text { the care team }\end{array}$ & $\begin{array}{l}\square \text { Each person works solo and is responsible } \\
\text { for their piece of work. There is no clear way } \\
\text { of sharing information or communicating }\end{array}$ & $\begin{array}{l}\square \text { The care approach is multidisciplinary and we } \\
\text { meet weekly to discuss topics, but we don't work } \\
\text { together as a team on a daily basis }\end{array}$ & $\begin{array}{l}\square \text { Care provided by a multidisciplinary team. } \\
\text { Overall, we function very well together as a team. } \\
\text { Information is key to the relationship and there are } \\
\text { clear ways to share information and communicate }\end{array}$ & $\begin{array}{l}\square \text { Can't }^{\prime} \\
\text { rate }\end{array}$ \\
\hline $\begin{array}{l}\text { Supportiveness of the } \\
\text { larger organisation }\end{array}$ & 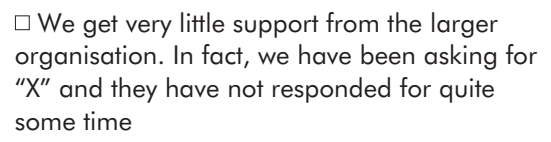 & $\begin{array}{l}\square \text { Getting help from the larger organisation has } \\
\text { been a mixed bag, sometimes we get what we ask } \\
\text { for but sometimes we don't }\end{array}$ & $\begin{array}{l}\square \text { The larger organisation is helpful, and in fact they } \\
\text { make it easier for us to meet the needs of our patients } \\
\text { and to work together as a team }\end{array}$ & $\begin{array}{l}\square \text { Can't }^{\prime} \\
\text { rate }\end{array}$ \\
\hline Constancy of purpose & $\begin{array}{l}\square \text { There is a lack of a clear consistent aim } \\
\text { that is communicated throughout our } \\
\text { microsystem }\end{array}$ & $\begin{array}{l}\square \text { The overall aim of our microsystem is clear to me, } \\
\text { but I don't think that it is clear to every one else } \\
\text { I work with }\end{array}$ & $\begin{array}{l}\square \text { There is a clear consistent aim that is integrated } \\
\text { throughout the microsystem. You can see it in our } \\
\text { everyday work }\end{array}$ & $\begin{array}{l}\square \text { Can't }^{\prime} \\
\text { rate }\end{array}$ \\
\hline $\begin{array}{l}\text { Connection to } \\
\text { community }\end{array}$ & $\begin{array}{l}\square \text { Our focus has been on our patients that } \\
\text { come into our unit. We have not done any } \\
\text { outreach programmes }\end{array}$ & $\begin{array}{l}\square \text { We have tried a few outreach programmes and } \\
\text { have had some success, but I would not say it is the } \\
\text { norm for us to go out into the community }\end{array}$ & $\begin{array}{l}\square \text { We are doing everything we can to understand } \\
\text { our community and we actively employ resources to } \\
\text { help us work with the community and define their needs }\end{array}$ & $\begin{array}{l}\square \text { Can't }^{\prime} \\
\text { rate }\end{array}$ \\
\hline $\begin{array}{l}\text { Investment in } \\
\text { improvement }\end{array}$ & $\begin{array}{l}\square \text { The training and resources are } \\
\text { not available for working on } \\
\text { improvement }\end{array}$ & $\begin{array}{l}\square \text { The resources (training, money, time) are available } \\
\text { for working on improvement, and we occasionally } \\
\text { use them }\end{array}$ & $\begin{array}{l}\square \text { The resources (training, money, time) are available } \\
\text { for working on improvement and we use them all } \\
\text { the time. Furthermore, improvement is a priority }\end{array}$ & $\begin{array}{l}\square \text { Can't }^{\prime} \\
\text { rate }\end{array}$ \\
\hline $\begin{array}{l}\text { Alignment of role and } \\
\text { training }\end{array}$ & $\begin{array}{l}\square \text { Everyone is not expected to work within the } \\
\text { limits of their education, certification (some } \\
\text { people are overqualified) }\end{array}$ & $\begin{array}{l}\square \text { For the most part the work everyone is expected to } \\
\text { do is appropriate for their skills and training }\end{array}$ & $\begin{array}{l}\square \text { Everyone is expected to work at the upper limits of } \\
\text { their education, training and licensure }\end{array}$ & $\begin{array}{l}\square \text { Can't }^{\prime} \\
\text { rate }\end{array}$ \\
\hline
\end{tabular}

